\title{
Selected legal problems of EEG biofeedback therapy under the Polish law
}

\author{
ALEKSANDRA NOWAK-GRUCA
}

\begin{abstract}
The use of EEG biofeedback for therapeutic or healing purposes has its justification in modern research and recently one can notice the increasing popularity of this method. Possible threats which may be associated with improper training and EEG biofeedback therapy may result from error in the diagnosis or incorrect selection of the training protocol. The effectiveness of therapy depends largely on the efforts of the patient himself, however, the range of waves will be amplified or suppressed by diagnosticians and therapists. If during an EEG biofeedback, the correct neuronal signal is amplified or suppressed, this can have adverse effects. In Poland, there are no legal regulations regarding the acquisition of qualifications for conducting neurotherapy. Likewise, there are no indications as to which institutions have the right to assign appropriate powers to use this type of apparatus. The lack of legal regulations means that now everyone can practice neurotherapy. The article presents selected legal problems related to conducting EEG biofeedback therapy under law, especially under Polish regulations, including the problem of the responsibility of the therapist or trainer.
\end{abstract}

Keywords: • EEG biofeedback • EEG applications • neurotheraphy • neurotherapist $\bullet$ legal liability $\bullet$ medical device $\bullet$ medical profession $\bullet$ patient's consent to treatment $\bullet$

Correspondence AdDress: Aleksandra Nowak-Gruca, Ph.D., Cracow University of Economic, Department of Civil and Economic Law, ul. Rakowicka 27, pokój 173 A, 31510 Krakow, Poland, e-mail: nowaka1@uek.krakow.pl.

DOI https://doi.org/10.18690/2463-7955.11.1.13-28.(2018)

ISSN 2463-7955

(C) 2018 University of Maribor Press

Available at http://journals.um.si/ 
The first measurements of brain's electrical activities were carried out on animals towards the end of the 19th century. In the 1920's a German researcher, by the name of Hans Berger, after having observed his son, made a detailed record of his brain's electrical activities. He introduced the nomenclature applicable in that area and coined the name electroencephalogram (EEG). His research was repeated in 1934 by Adrian and Matthews (Rowan and Tolunsky, 2004: 14). For its part, the combination of biofeedback and electroencephalogram was an accomplishment of Japanese psychologist Joe Kamiya. Kamiya proved that man can independently tell when his brain produces alpha (brain) waves. According to his assumption, Kamiya confirmed that in order to achieve that a modification of the subject's mental state is necessary, based on the received feedback information. In order to verify these hypotheses, the psychologist asked a randomized patient to say if, at any given time, he emits alpha waves. A positive response was properly reinforced to such an extent that after four days the subject made only correct indications and was even able to provoke such conditions. In this connection, the scientist decided to construct a device that would provide test subjects with feedback in the form of sound. Measurement of the discussed biological processes took place by monitoring electrical activities of cells, or brain waves, through electrodes attached to the scalp. Results of such measurement were then displayed on a computer screen (Okupińska and Krzywowiąza, 2013: 201). The person generally recognised as the inventor of this method was M. Barry Sterman, who initiated therapeutic application of biofeedback. In the 1960's at the University of California, he carried out thorough tests on cats and, with the use of the instrumental conditioning method, evidenced that itwas possible (even for those animals) to increase the amplitude of certain characteristic brain waves, which amplitude, in consequence, immunizes against epilepsy attacks. Sterman implemented his studies in the human context and, using the same method, increased the sensorimotor rhythm (SMR) in patients with epilepsy. The work with biofeedback resulted in the reduction of frequency, duration and intensity of attacks in the subjects. As he continued his studies in cooperation with Joel Lubar, he observed that a considerable group of epileptic patients also had disorders relating to hyperactivity. Also, in their case, the use of the SMR method produced positive results. Lubar decided to expand the subject area of his work by children with attention deficit hyperactivity disorder (ADHD) and in cooperation with MargarethShouse, in 1976 and 1979, he co-authored publications on the treatment of children with ADHD (Walkowiak, 2015: 312). A barrier for popularization of neurofeedback was, for a long time, a costly piece of necessary equipment. Only once personal computers became commonplace at the beginning of the 1990's did the prices of such devices decrease. A second barrier for the development of neurofeedback was an initial lack of understanding in professional circles. A method invoking such concepts as will, conscience or selfregulation reached beyond the then applicable "mechanistic" paradigm of natural sciences. Presently, a rapid development of different forms of neurotherapy can be 
observed. ${ }^{1}$ Witheach year, the number of scientific publications in that area increases. There are organizations and associations that deal with research in and popularization of the said method (e. g. the Association for Applied Psychophysiology and Biofeedback (AAPB) in the USA, ${ }^{2}$ and the Biofeedback Federation of Europe, the International Society for Neurofeedback \& Research (ISNR) in Europe).

EEG biofeedback training is generally considered safe. Noticeable training effects require intense and systematic work. In this connection, just as one has to wait a while for positive effects, undesired ones would also take time. In literature, it is indicated that possible threats that may relate to incorrect course of training and EEG biofeedback therapy may be a consequence of an error in diagnosis or inappropriate selection of the training protocol. Although effectiveness of the therapy depends in large measure on the efforts of the patient himself, diagnosticians and therapists are the ones that decide about the range of waves to be amplified or suppressed. If, in the course of biofeedback, the correct neuronal signal is amplified or supressed excessively, this can lead to undesired results (Rogel et al., 2015: 209-218). Therefore, the safety of neurofeedback is compared to sports where mismatched or excessively intense exercises may produce negative results (Szewczyk, Siedlecki and Ratomska, 2016: 21-27).

In Poland, the most popular method of neurotherapy is EEG biofeedback. EEG Biofeedback training consists of learning-based practice on instrumental conditioning (desired behaviour is rewarded) by providing the trained person with feedback signals on the changes of the physiological condition of his organism, thanks to which one may learn to consciously modify certain functions (in this case, brain waves), which are not normally consciously controlled. A crucial role in neurofeedback therapy is played by flexibility of the brain, which is the ability of brain cells to create new connections and regeneration of the existing ones (Warraich and Kleim, 2010: 208-219). It is assumed in EEG biofeedback therapy that the way in which neuroconduction processes occur in the human brain translates into the person's behaviour, since the cerebral cortex fulfils the function of central regulation of the processes of thinking and behaviour. In the discussed method, it is assumed that by exerting influence on neuroconduction in the human brain, with the aid of biofeedback training, one may achieve enhancement or suppression of communication between different areas of the cerebral cortex, and, consequently, significant and durable psychophysiological changes (Walkowiak, 2015: 219).

EEG biofeedback -method of treatment or enhancement of a human being?

EEG biofeedback therapy is not listed by organizations related to health as a method of treatment, however, in the International Classification of Diseases (International 
A. Nowak-Gruca: Selected legal problems of EEG biofeedback therapy under the Polish law

classification system for surgical, diagnostic and therapeutic procedures: ICD-9$\mathrm{CM}$ version 5.36), Biofeedback therapy can be found under the name "Individual psychotherapy - others (94.39)."

In Polish literature of this subject, it is often pointed out that the EEG biofeedback method is one of instrumental psychotherapy methods (Pakszys and Pakszys, 2018), but authors also point to the non-therapeutic use of neurofeedbackfor peak performance training, which develops mental potential and increases resistance to stress.

Among medical uses of neurobiofeedback, in the first group of scientifically confirmed applications of the method one can list seizure disorders and attention deficit disorder $\left(\mathrm{ADD}^{3}\right.$ ) (Alhambra, Fowler and Alhambra, 1995: 39-43). In the second group, which still requires further examination, there are: treatment of depressive moods (Cheon, Koo and Choi, 2016: 103-110), treatment of addictions (Kim et al., 2015: 1552-1572), assistance to patients with closed head injury and traumatic brain injury (Hammond, 2007: 57-62) and working with children who have learning disabilities (Orlando and Rivera, 2004: 5-19). The third group comprises uses which seem promising in light of reported clinical improvements, but which still have not been verified. This group includes: Tourette's syndrome and other movement disorders (Parkinson disease, dystonia), Asperger's syndromeand autism (Coben, Mohammad-Rezazadeh and Cannon, 2014: 45), epilepsy, "brightening of the mind" in elderlypersons (Albert et al., 1998: 109), obsessive-compulsive disorders (Raymond et al., 2005: 195-201) and generalized anxiety disorder (Hammond, 2005: 131-137). Moreover, the following advantages of the discussed method are mentioned: mental and emotional relaxation, acquisition of relaxing skills, improvement to mental healthcondition, acquisition of skills to control emotions, synchronization of cerebral hemispheres and improvement of brain capacities (Fehmi and Selzer, 1980).

The above mentioned shows that EEG-Biofeedback therapy may be a method of treating people or supporting treatment (Krekora and Czernicki, 2005: 26-30). It may also serve as training received with a view towards harmonizing and achieving greater stabilization of brain activities, and, in the same way, improving intellectual and physical capacities (Boynton, 2001: 5-18). In this sense, biofeedback training can be characterized as a human enhancement, which relates to the trend referred to as transhumanism, based on the assumption of improving human beings and the possibility to establish control over ever wider areas of ones activities, both physically and intellectually (President's Council on Bioethics, 2003). It is assumed that enhancement does not address medical conditions but interferes in a healthy organism, properly functioning body or psyche with a view towards widening or optimizing its capacities, and, in the same way, increasing chances for a good life in specific circumstances. It has been frequently identified with a radical intervention or one that improves different types of properties, generally attributed 
to people, involving the setting of new "enhanced" parameters (Parens, 1998). Improvement of human nature is often juxtaposed against such concepts, such as treatment or therapy applicable once a specific disease has been diagnosed (Domaradzki, 2013:9). As a consequence, it seems that a key role in the differentiation between EEG biofeedback as a method of treatment or a method supporting treatment, on one hand, and training, on the other, should be assigned to the notions of health and disease. While attempting to define them, it is worth referring to the concepts developed by the World Health Organization (WHO). In light of the latter, health is a condition characterized by the achievement of physical, mental and social well-being. Disease, for its part, means every disorder (destruction or deviation) of the appropriate structure or function of any part, organ or system of the organism, manifest in a characteristic set of symptoms, whose aetiology, pathology and prognosis may be either known or unknown. As a result, where EEG biofeedback training is used to remedy disorders or alleviate symptoms of a disease, it will be a method related to human treatment, and where it is used to improve mental potential, neurofeedback will be viewed as a training set in the wider context of human enhancement. One should also point to the worldwide use of the biofeedback method in research and experiments. In effect, as far as legal qualifications are concerned, these problems seem highly complex and require ordering, optimally, in the form of a deliberate legislative intervention.

\section{Does biofeedbackequipment fall within the concept of "medical device"?}

In EEG biofeedback treatment, the following equipment components are applied: electrodes used in electroencephalography, biological amplifier caps, computer or laptop for the tester, screen/monitor used by the subject and additional control devices (e.g. sound alarm, light). The most frequent further components in the available sets include: necessary software and training boards (training session models). In consequence, a question arises if we have to do with a medical device which requires certification and is subject to regulation in terms of placement on market?

Significant influence on interpretation of the definition of "medical device" is exerted by the judgment of the Court of Justice of the European Union (hereinafter: CJEU) of 22 November 2012 in the case C 219/11. At the beginning of the judgement, it is worth pointing out that under the Council Directive 93/42/EEC of 14 June 1993 concerning medical devices, a »medical device« means any instrument, apparatus, appliance, material or other article, whether used alone or in combination, along with all furnishings, including software intended by its manufacturer for special use involving diagnostic or therapeutic purposes and necessary for its proper application, intended by the manufacturer to be used for human beings for the purpose of: 
A. Nowak-Gruca: Selected legal problems of EEG biofeedback therapy under the Polish law

- diagnosis, prevention, monitoring, treatment or alleviation of disease,

- diagnosis, monitoring, treatment, alleviation of or compensation for an injury or handicap,

- investigation, replacement or modification of the anatomy or of a physiological process,

- control of conception.

and which does not achieve its principal intended action in or on the human body by pharmacological, immunological or metabolic means, but which may be assisted in its function by such means.

In the cited ruling, the CJEU indicated that Directive 93/42 may trigger restriction of the free movement of medical devices by imposing an obligation of certification and $\mathrm{CE}$ marking exclusively where such restriction is necessary to protect public health. Moreover, if a device has not been created by the manufacturer for a use relating to medical purposes, its certification as a medical device may not be required. To exemplify such a situation, the judgment invokes the case of numerous sporting goods that allow the taking of measurements of operation of certain organs in the human body with the exception of use for medical purposes. If such goods were to be considered medical devices, they would be subject to a certification procedure, and this is by no means justified. In response to the referred preliminary question, the Court held that in the context of art. 1(2)letter a) of Directive 93/42 and purposes of the indicated piece of legislation, the concept of device intended by the manufacturer to be used for human beings with the purpose of examining the physiological process should be interpreted so that the term "medical device" covers an object created by the manufacturer for use in human-beings to examine the physiological process exclusively where it is intended for medical purposes.

As a result, in light of the foregoing investigations, it seems that certification of biofeedback equipment will not be necessary if it is not used for medical purpose, but rather for training purposes.

In Poland, the term medical device is defined in art. 2(1) item 38 of the Medical Devices Act. ${ }^{4}$ The biofeedback devices offered on the Polish market generally have a CE medical certificate and are usually classified according to the Regulation of the Minister of Health on the classification of medical devices ${ }^{5}$ under class II-A, taking into consideration the risk of their application. In this context, a problem arises of appropriate entitlements of a non-physician neurotherapist to qualify a patient for the application of a medical device. Although the Act itself does not provide for any restrictions in this respect, in the event of a court dispute the entitlement of such person to apply biofeedback equipment as medical device may be brought into question. In this context, the problem of professional qualifications of a neurotherapist becomes manifest. This issue calls for a wider discussion. 


\section{The problem of professional qualifications of a neurotherapist}

In Poland there are no legal provisions on the acquisition of qualifications to practice neurotherapy. Similarly, there are no indications concerning the institutions empowered to grant respective entitlements to operate equipment of such type. ${ }^{6}$ The absence of legislation leads to a situation in which, at the time being, everyone may conduct neurotherapy. In practice, however, these are psychologists, educators, teachers, occupational therapists, social workers, and, increasingly, physicians. Whereas EEG biofeedback trainings conducted by physicians are governed by the provisions of medical law (especially the Physician and Dentist Professions Act ${ }^{7}$ and the Therapeutic Activities Act ${ }^{8}$ ), the legal basis for carrying out neurotherapy by non-physicians is unclear.

In this context, it is worth considering if a neurotherapist who is not a physician falls within the concept of "health professional" in the understanding of the Therapeutic Activities Act. Under art. 2(1) item 2 of the cited legislative act, the term refers to:

- a person who, under separate legislation, is entitled to provide medical services, and

- a person who acquired professional qualifications to provide health services within a specific scope or in a specific field of medicine.

The concept ofpracticing a "health profession" relates to individuals who, on a permanent basis, pursue a professional career in an ocupation relating to medicine and who have proper qualifications. By qualifications, one should understand the stock of knowledge and skills required to provide health services. The concept of health professionals covers persons practicing professions whose status is defined in statutory law and ones which, under the present legislative framework, lack such regulation (Kolosa, 2000: 54). It seems that the expression used in the cited Act enables inclusion of a non-physician neurotherapistin the group of persons holding professional qualifications to provide medical services within a specific scope or in a specific field of medicine, as long as the qualifications held by such a therapist authorize provision of widely understood health services. The above statement is confirmed in the judgment of the Voivodeship Administrative Court in Szczecin of 8 October 2013 (I SA/Sz 464/13, LEX No. 1382020), in which the Court held that a neurotherapist is a person pursuing a health profession mentioned in art. 2(1)item 2 of the Therapeutic Activities Act, as a part of which he provides medical care services aimed at restoration and improvement of health. Going further and assuming that neurotherapy has an application in medicine or, within a wider perspective, in health protection, we may conclude that the term neurotherapist also falls under the definition of "health professional". 
However, it follows from the reasoning set out in the previous subchapter that the EEG biofeedback method may be used not only for the purpose of restoring and improving health but also as a part of training understood broadly as enhancement of human beings. Therefore, there is some doubt if, in the latter case, a neurotherapist is actually a person pursuing a health profession. It seems that it is not the case. As pointed out, in Polish law the problems of professional qualifications of neurotherapists have not been regulated. There is also no statutory framework of the psychotherapist profession, and the framework of the psychologist profession, in the light of missing implementing regulations under the Psychologist Profession Act, is considered "inoperative" (Żukowski, 2017: 39). These questions are not irrelevant to the problems of neurotherapy's safety and legal liability relating to EEG biofeedback trainings.

\section{Civil liability for the use of the EEG-Biofeedback method. Selected problems.}

The therapy and trainings with the biofeedback method are conducted within the therapist-patient framework, with the use of appropriate technologies. The EEG biofeedback system is used in sessions with persons of different age and, depending on the needs of particular individuals, such sessions are appropriately structured and modulated so as to ensure their high efficiency and full effectiveness. It is argued that a very important element of the therapy is the diagnosis of the client's (patient's) present psychophysical condition, established most often by way of an interview or during a test with qualitative encephalography, which, in effect, provides information on the general immunity and psychoneurophysical level. On such a basis, appropriate protocols are selected and the planned number of work sessions with biofeedback is determined. All of that is done while taking the expected results into consideration. Adjustment of the course of therapy or trainings with the use of EEG biofeedback is one of the tasks of the therapists, who should have appropriate qualifications to conduct this type of activities. During each work session with EEG biofeedback, the client experiences different psychic conditions, which means that mentally he is very active. In the context of the above, it seems that the client-therapist relationship should be based on trust and that the client consciously expressed consent to such influences. In the absence of respective provisions in Polish law governing the administration of psychotherapy or neurotherapy, it seems that the requirements that relate to patient's consent to a medical procedure should be applied appropriately.

In international law, an important piece of legislation governing the question of patient's consent to a medical procedure is the Convention for the Protection of Human Rights and Dignity of the Human Being with regard to the Application of Biology and Medicine, ${ }^{10}$ which requires that a medical intervention should be preceded by expression by the patient of free and informed consent. Poland signed the Convention and the Additional Protocol on the Prohibition of Cloning Human 
Beings on 7 May 1999, but has not yet ratified those documents. In Polish law, the requirement of a patient's consent during the treatment process is enshrined in art. 41(1) of the Constitution of the Republic of Poland. Polish medical law literature and judicial practice use the terms: "conscious consent" "informed consent" or "instructed consent", which all relate to the consent of a patient adequately informed by the physician. ${ }^{11}$ It is assumed that a legally valid consent to a medical procedure may only be given by a conscious patient, i.e. one with appropriate knowledge of the reasons for the intervention, its risk, effects and consequences relating to its omission. At the same time, non-performance or undue performance by a physician of the disclosure obligation, i.e. omission to make the patient informed (aware), nullifies his consent and, in consequence, may result in holding the physician liable professionally, civilly and criminally (Nesterowicz, 2013: 163). Although this question remains unregulated in Polish law, in the context of EEG biofeedback therapy-both when conducted in relation to a disease and merely for training purposes -I think that the therapist should fulfil his disclosure obligations to a degree that permits the client's conscious consent to the implementation of the discussed method, especially that it requires him to actively cooperate and become engaged in the improvement of his own health. In addition, this therapy is longlasting and time-consuming. Moreover, in Poland it is not presently reimbursed. ${ }^{12}$ Nevertheless, without proper statutory regulation the possibility to legally enforce such an obligation is limited in Polish law exclusively to physicians who apply neurotherapy.

The legal bond between the neurotherapist and the client (patient) arises under a contract, which does not require any special form. In Polish law, contractual duties are assigned the status of either obligations of means or obligations of result. Under an obligation of means, the obliged person is bound to act to his best knowledge and will, within the limits specifiedin the agreement. An obligation of result implicates the achievement of a specific product, effect or factual consequence. In principle, a neurotherapist incurs an obligation of means to use his knowledge, skillset and professionalism in the provided services. Consequently, a contract concluded between a therapist and a patient constitutes an obligation of means, to which provisions on the mandate contract apply appropriately (art. 750 of the Civil Code). It should be considered when, in the context of therapy or EEG biofeedback training, one can speak of non-performance or undue performance of an obligation.

While the legal situation of a physician conducting neurotherapy is governed by appropriate provisions of medical law, as far as other persons are concerned one can only refer by analogy to the legal situation of a physician. As a result, just as in the case of physicians, undue performance of the obligation will consist in:

- diagnostic error- incorrect identification of the patient's ailment by the neurotherapist, covering both the absence of any diagnosis and incorrect 
diagnosis of a sickness or disorder, as a result of which the neurotherapist was unable to apply the correct therapy;

- therapeutic error - incorrect measure applied despite the correct and effective diagnosis of the patient's problem, implemented contrary to therapeutic art, by use of inappropriate treatment instruments, inappropriate application of instruments, which are adequate for the therapy of any specific disorders, application of a method which has been objectively wrongly chosen for the psycho-health situation of the patient. As regards EEG biofeedback therapy, this may amount to application of an incorrect therapeutic protocol (e.g. suppression instead of amplification of a given electroencephalographic range) (Szewczyk, Siedlecki and Ratomska, 2016: 25).

Occurrence of the above errors results in undue performance of the obligation. However, omission to take any measures despite a duty incurred by the therapist will amount to non-performance of such obligation. These errors may be committed by a neurotherapist both by acts and omissions. Thus, an error is made not only by a neurotherapist who takes measures that result in an incorrect diagnosis, but also by one who does not take any measures to establish the correct diagnosis. Similarly, an error is committed not only by a neurotherapist who applies improper therapy, but also by one who omits to apply a therapy that should be implemented in the given circumstances (Szewczyk, Siedlecki and Ratomska, 2016: 25).

In my opinion, regardless of the legal bases for the provision of EEG biofedback services and nature of the relationship (physician - patient; therapist - patient; trainer - client), the obligation incurred by a neurotherapist remains an obligation of means, where the neurotherapist is bound to exercise care in each aspect of his contacts with the client and at every stage of the therapy. It seems that such care should be especially great in the context of the professional (expert) character of the neurotherapist's activities and the fact that the subject matter of such activities are physical and intellectual capacities of a human being (art. $355 \S 2$ of the Civil Code). Any defection from the level of care required from the therapist's actions in the specific circumstances will amount to his fault. As far as liability of a neurotherapist is concerned, just as in the case of that of a physician, a given action will be subjectively culpable if it follows from a comparison of the activities of a given neurotherapist (applying a specific training model in particular circumstances) with a model of appropriate action applicable to thetherapist that in the same circumstances the model "good neurotherapist" would not cause damage to the client. Apart from negligence (lack of due care), fault may also consist in awkwardness or inattention of the therapist, or a common forgetfulness or oversight (e.g. omission of necessary diagnostic examinations), lack of caution or foresight, which may result in a damage inflicted to a patient. It seems as well that a neurotherapist should be liable for every civil fault, even the slightest one, both 
where the claims are based on delictual (tortious) grounds and also where the injured party relies on the regime of contractual liability.

These circumstances will be modified by additional obligations of a neurotherapist following from the professional character of the activities, representations made to the client, as well as norms and internal rules governing the profession practiced. However, it should be stressed once again that the legal framework of conducting neurotherapy is most transparent for physicians, and with regard to other therapists the legal standards developed for that profession may only be applied by analogy.

\section{Conclusions}

EEG biofeedback is quite a new method of influencing physical and mental health of human beings, something which entails numerous challenges. The area of application of EEG biofeedback is vast and it is argued that a therapy or trainings may lead to multidimensional changes in the functioning of a given person. It is pointed out that the use of EEG biofeedback for therapeutic or medical purposes is justified by contemporary scientific reports, and one can recently observe a clear development in scientific research devoted to this method. However, there are also doubts among experts as to the effects of such therapy. Sometimes scientists question the efficiency of the method, its legitimacy and criteria of selection of the group of its addressees.

In this article, against the background of the history of the method and scientific insights in the possible areas of its use, I decided to examine the legal issues relating to its application. In particular, attention was paid to the need to distinguish between neurotherapy understood as a method of treating human beings and training which may be qualified as a widely conceived method of enhancement, the latter involving exertion of influence with the use of accessible technologies on physical and intellectual fitness of individuals. In the absence of respective rules in Polish legislation on the psychotherapist profession, doubtful provisions on the psychologist profession and missing legal framework for neurotherapy, it was necessary to consider the problems of professional qualifications of a neurotherapist and qualification of the apparatus used in the discussed method. Whereas application of the EEG biofeedback method by physicians is governed by the provisions of medical law, as regards provisions of such services by other persons (in practice, these are mostly psychologists, educationists, teachers, occupational therapists, social workers), the absence of a legal framework for the said activities gives rise to the question about the limits of liability for diagnostic and therapeutic errors. It was proposed in the article that in the event of use of neurotherapy as a method of treatment or method supporting treatment, the legal standards developed for physicians with regard to pursuance of their profession should, by analogy, apply also to neurotherapists. It seems, however, that in the context of application of the biofeedback method for training purposes (enhancement), on account of the 
possibility to affect psychosomatic and neurological processes and mental ability of human beings, the increased standards of care should apply for the liability for services provided with the use of neurotherapy methods. In addition, due to the fact that such therapy is long-ranged, requires active cooperation and involvement from the addressee and is not reimbursed in Poland, the precondition of legality of its implementation should be the client's "conscious consent". A neurotherapist should comply with the obligation to provide detailed information to the client concerning the reasons, consequences and possible effects of the method. Unfortunately, because of the missing statutory provisions on the implementation of neurotherapy in Poland, there are no legal indications regarding who, on what terms and with the use of what apparatus may conduct such therapy. The postulated application of the increased standards prescribed by legislation for physicians will not always be possible. Besides, holding a neurotherapistdelictually (tortiously) or contractually liable for a defective therapy or training is not easy in light of ongoing controversies and disputes in science concerning the effects, harmfulness and preconditions of the application of the EEG biofedback method. As a result, further scientific investigations of this method are needed, as well as further investigations of legal issues. Presently, one can only postulate inclusion of a part of the problems signalledin this article in the ever-recurring discussion in Poland about the shape of the Psychotherapist Profession Act. It seems that such a piece of legislation could be a good place for regulating problems relating to neurotherapy and other methods supporting treatment processes or methods of human enhancement, which can be expected to flourish in the near future.

\section{Acknowledgment}

This article makes a fragment of the research project No. 2017/01/X/HS5/00002 financed from the funds of the National Science Centre (NCN).

\section{Notes}

The letters 'CE' appear on many products traded on the extended Single Market in the European Economic Area (EEA). CE marking is a certification mark that indicates conformity with health, safety, and environmental protection standards for products sold within the EEA.

${ }^{1}$ Medical and psychological literature restricts neurotherapy exclusively to influences by non-pharmacological means. These include EEG-biofeedback/neurofeedback and transcranial magnetic stimulation or transcranial direct current stimulation (TMS, tDCS), for more see Brunoni, Nitsche, Bolognini, 2012: 175-195.

2 The Association for Applied Psychophysiology and Biofeedback (AAPB) was founded in 1969 as the Biofeedback Research Society. The goals of the association are to promote a new understanding of biofeedback and advance the methods used in this practice. AAPB's mission is to advance the development, dissemination and utilization of knowledge about applied psychophysiology and biofeedback, to improve health and the quality of life 
through research, education and practice. https://www.aapb.org/i4a/pages/index.cfm?pageid=3285 (access: 26.01 .2018 )

${ }^{3}$ ADD (Attention Deficit Disorder) - attention deficit disorder without, or with low motor hyperactivity. ADD is diagnosed as a derivative of $\mathrm{ADHD}^{4}$ Act of 20 May 2010, consolidated text: Dz. U. 2017, item 211, as amended.

${ }^{5}$ Regulation of the Minister of Health of 5 November 2010, Dz. U. No. 215, item 1416.

${ }^{6}$ In the classification of professions and specialties for the purposes of the labour market (Regulation of the Minister of Labour and Social Policy on the classification of professions and specialties for the purposes of labour market and the scope of its application of 7 August 2014, Dz. U. 2014, item 1145), neurotherapist was not listed in the group "Health Professionals" (group 22). Similarly, it was not included in the classification of professions covered by the vocational education system (Regulation of the Minister of National Education of 13 March 2017, Dz. U. 2017, item 622).

${ }^{7}$ Act of 5 December 1996 on the professions of physician and dentist, Dz. U. 2017, item 2371, as amended.

${ }^{8}$ Act of 15 April 2011 on therapeutic activities, Dz.U. 2018, item 160, as amended.

${ }^{9}$ In the literature of the subject, a "health professional" is a person with medical education sensustricto, e.g.: physician, nurse, midwife, pharmacist or other medical one, e.g. dentist technician, or education applicable in medicine, and, in a wider perspective, in health-care, e.g. psychotherapist, who has appropriate rights to practice his profession, e.g. license for the practice of medicine, proper certificate, diploma. (Fiutak, 2013; Fiutak and Dąbrowski, 2012)

${ }^{10}$ Convention on Human Rights and Biomedicine of 4 April 1997. Later, it was supplemented by four additional protocols: Additional Protocol on the Prohibition of Cloning Human Beings (1998); Additional Protocol on Transplantation of Organs and Tissues of Human Origin (2002); Additional Protocol on Biomedical Research (2005); Additional Protocol Concerning Genetic Testing for Health Purposes (2008).

${ }^{11}$ See judgment of the Supreme Court of 23 November 2007, IV CSK 240/07, LexPolonica No. 1900385, OSNC 2009, No. 1, item 16.

${ }^{12}$ It is different e.g. in the USA, where US insurance companies cover the costs of treatment of attention disorders with such methods.

\section{References}

Achinivu, K., Staufenberg, E., Cull, C. (2012) Cognitive function during vagus nerve stimulation for treatment-refractory epilepsy: A pilot study using the critical flicker fusion test, Journal of Neurotherapy, 16(1), pp. 32-36, doi: 10.1080/10874208.2012.650097

Albert, A. O., Andrasik, F., Moore, J. L., \& Dunn, B. R. (1998) Theta/beta training for attention, concentration and memory improvement in the geriatric population, Applied Psychophysiology \& Biofeedback, 23(2), pp: 109. Abstract.

Alhambra, M. A., Fowler, T. P., \& Alhambra, A. A. (1995) EEG biofeedback: A new treatment option for ADD/ADHD, Journal of Neurotherapy, 1(2), pp. 39-43, doi: 10.1300/J184v01n02_03

Barabasz, A., \& Barabasz, M. (1996) Neurotherapy and alert hypnosis in the treatment of attention deficit disorder, In: Lynn, S. J., Kirsch, I. \& Rhue, J. W. (eds.) Casebook of Clinical Hypnosis (Washington, D.C.: American Psychological Association Press), pp. 271-292 
A. Nowak-Gruca: Selected legal problems of EEG biofeedback therapy under the Polish law

Boynton, T. (2001) Applied research using alpha/theta training for enhancing creativity and well-being, Journal of Neurotherapy, 5(1-2), pp. 5-18, doi: 10.1300/J184v05n01_02.

Brunoni A. R., Nitsche M. A., Bolognini N., et al. (2012) Clinical research with transcranial direct current stimulation (tDCS): Challenges and future directions, Brain Stimulation, 5(3), pp. 175-195, doi: 10.1016/j.brs.2011.03.002.

Cheon, E. J., Koo, B. H. \& Choi, J. H. (2016) The efficacy of neurofeedback in patients with major depressive disorder: an open labeled prospective study, Applied Psychophysiology \& Biofeedback, 41(1), pp. 103-110, doi: 10.1007/s10484-0159315-8.

Coben, R., Mohammad-Rezazadeh, I. \& Cannon, R. (2014) Using quantitative and analytic EEG methods in the understanding of connectivity in autism spectrum disorders: a theory of mixed over- and under-connectivity.Frontiers in Human Neuroscience, 8 , pp. 45, doi: 10.3389/fnhum.2014.00045.

Cordelia, R., Anderson, J.S (2012) Evaluation of neurofeedback training in the treatment of parkinson's disease: A pilot study, Journal of Neurotherapy, 16(1), pp. 4-11, doi: 10.1080/10874208.2012.650109.

Domaradzki J. (2013) O definicjach zdrowia i choroby, Folia Medica Lodziensia, 40(1), pp. 5-29.

Fehmi, L. G. \& Selzer, F. A. (1980) Biofeedback and attention training, In S. Boorstein (Ed.), Transpersonal Psychotherapy (Palo Alto: Science and Behavior Books).

Fiutak, A. (2013) Prawo w medycynie (Warszawa: CH-Beck), pp. 23-50.

Fiutak, A. \& Dąbrowski, J. (2012) Udzielanie pomocy terapeutycznej. Aspekty prawne, (Warszawa: Difin), pp. 17-54.

Hammond, D. (2005) Neurofeedback treatment of depression and anxiety, Journal of Adult Development, 12(2/3), pp. 131-137, doi: 10.1007/s10804-005-7029-5.

Hammond, D. C. (2007) Can LENS neurofeedback treat anosmia resulting from a head injury?, Journal of Neurotherapy, 11(1), pp. 57-62, doi: 10.1300/J184v11n01_06.

Kim, D. Y., Yoo, S. S., Tegethoff, M., Meinlschmidt, G. \& Lee, J. H. (2015) The inclusion of functional connectivity information into fMRI-based neurofeedback improves its efficacy in the reduction of cigarette cravings, Journal of Cognitive Neuroscience, 27(8), pp. 1552-1572, doi: 10.1162/jocn_a_00802.

Kolosa, A. (2000) Zdaniem Państwowej Inspekcji Pracy, Praca i Zabezpieczenie Społeczne, 7-8, pp: 54 - 56.

Krekora, K. \& Czernicki, J. (2005) Biofeedback in rehabilitation of stroke patients, Rehabilitacja Medyczna, 9(3), pp. 26-30.

Nesterowicz, M. (2013) Prawo medyczne (Toruń: Dom OrganizatoraTNOiK)

Okupińska, A. \& Krzywowiąza, A. (2013) Biofeedback jako efektywna metoda w terapii deficytów poznawczych w ujęciu teorii umysłu. Neurokognitywistyka w patologi I izdrowiu 2011-2013, Roczniki Pomorskiej Akademii Medycznej w Szczecinie, 3, pp. 195-202.

Orlando, P. C., \& Rivera, R. O. (2004) Neurofeedback for elementary students with identified learning problems, Journal of Neurotherapy, 8(2), pp. 5-19, doi: $10.1300 / \mathrm{J} 184 \mathrm{v} 08 \mathrm{n} 02 \_02$.

Pakszys M. \& Pakszysz W. (2018) EEG Biofeedback - metodaneuroterapiiinstrumentalnej, available at: http://www.psychiatria.pl/artykul/eeg-biofeedback-metodaneuroterapii-instrumentalnej/653 (January 31, 2018).

Parens, E. (1998) Enhancing Human Traits: Ethical and Social Implications (Georgetown: Georgetown University Press). 
President's Council on Bioethics (2003) Beyond Therapy: Biotechnology and the Pursuit of Happiness (Washington, DC: President's Council on Bioethics).

Raymond, J., Varney, C., Parkinson, L. A., \& Gruzelier, J. H. (2005) The effects of alpha/theta neurofeedback on personality and mood, Cognitive Brain Research, 23(23), pp. 287-292,

Sürmeli T, Ertem, A. (2011) Obsessive compulsive disorder and the efficacy of qEEG-guided neurofeedback treatment: a case series, Clinical EEG Neuroscience Journal, 42(3), pp. 195-201.

Rogel, A., Guez, J., Getter, N., Keha, E., Cohen, T., Amor, T. \& Todder, D. (2015) Transient adverse side effects during neurofeedback training: a randomized, sham-controlled, double blind study, Applied Psychophysiology \& Biofeedback, (40) 3, pp. 209-218. doi: 10.1007/s10484-015-9289-6

Rowan, A. J. \& Tolunsky, E. (2004) Podstawy EEG z mini atlasem (Wrocław: Urban \& Partner)

Schütze, M., Junghanns, K. (2015) The difficulty of staying awake during alpha/theta neurofeedback training, Applied Psychophysiology \& Biofeedback, 40(2), pp. 85-94. doi: 10.1007/s10484-015-9278-9.

Szewczyk, R. Ł., Siedlecki, M. Ł. \& Ratomska, M. A. (2016) Prawne aspekty prowadzenia i korzystania z neuroterapii, Neuropsychiatria i Neuropsychologia, 11 (1), pp. 2127, doi: 10.5114/nan.2016.60392.

Walkowiak, H. (2015). EEG biofeedback: charakterystyka, zastosowanie, opinie specjalistów, Studia Edukacyjne (Adam Mickiewicz University Press), 36, pp. $307-$ 325, doi: $10.14746 / \mathrm{se} .2015 .36 .18$

Warraich, Z. \& Kleim, J. A. (2010) Neural Plasticity. The biological substrate for neurorehabilitation. $P M \& R ; 2$ (12), pp. 208-219, doi: 10.1016/j.pmrj.2010.10.016.

Żukowski, L. J. (2017) Psycholog jako zawód zaufania publicznego - wybrane problem Teza nr. 2, Przeglad Prawa Publicznego, 3, pp. 39-49. 
